\title{
O Imperativo do Financiamento e da Gestão: Desafios ao Sistema Único de Saúde
}

THE IMPERATIVE OF FINANCING SUPPORT AND MANAGEMENT: CHALLENGES FOR THE SISTEMA ÚNICO DE SAÚDE

Marcelo Gouvêa Teixeira ${ }^{(*)}$

\section{RESUMO}

A trajetória percorrida pelo Sistema Único de Saúde - SUS, desde a Constituinte de 86, apresenta êxito na definição e implementação de seu arcabouço institucional. Porém, esse desempenho não se desdobrou em um modelo de financiamento capaz de assegurar recursos necessários à sua manutenção.

O atual debate acerca do financiamento da política pública de saúde encontra na implementação e regulamentação da Emenda Constitucional $n$. 29 de 2000 seu principal mote. Trata-se de questão cujo desfecho provocará desdobramentos estratégicos para a construção do Sistema Único de Saúde.

Propõe-se a abordagem dessa discussão em dois níveis. O primeiro, de enfoque tático-conjuntural, situa-se em torno da Emenda propriamente dita e de sua regulamentação. As questões concentram-se na natureza do avanço conquistado com a sua promulgação e os riscos de retrocesso na elaboração da lei complementar. É possível entendê-la como uma medida que proporciona, ao mesmo tempo, previsibilidade de recursos, mas que também define limites à política. O segundo, de caráter estratégico, problematiza a própria trajetória perseguida pela política setorial em busca da garantia constitucional do financiamento, procurando compreender como um movimento tão bem sucedido enfrenta dificuldades na operacionalização de uma conquista constitucional. Indaga-se ainda a sustentação que a sociedade brasileira, mediante seus governos eleitos, fornece ao Sistema

(*) Mestre em Administração, servidor público federal da carreira de Especialista em Políticas Públicas e Gestão Governamental, atualmente exercendo o cargo de Subsecretário na Secretaria de Estado de Saúde de Minas Gerais. 
Único de Saúde. Do encontro dessas vertentes, depreende-se contribuições para enfrentamento da questão da regulamentação no curto prazo e enseja elementos para a agenda de construção do Sistema. Não se empreende uma análise exaustiva das questões apresentadas, mas apenas um inventário de questões a título de contribuição ao debate.

\section{Palavras-chave}

Financiamento, políticas públicas de saúde, gestão.

\section{ABSTRACT}

All the distance surpassed by the Sistema Único de Saúde- SUS, since the 86 Constitution, shows the successful implementation and definition of its institutional framework. However, the successful performance does not turn into a financing model, capable of assuring the necessary sources for its support.

The present debate of the monetary support of the public health politics is outlined by the implementation and regularization of the Constitutional Amendment $n .29$ of 2000 . It is a subject which conclusions will cause strategic changes for the building of the SUS.

This article proposes a two level approach of this question. First, a tactic approach is located on the Amendment itself and its regulation. The problem here concerns about the nature of the advance obtained with the promulgation of the Amendment and the risks of retrogression during the creation of a supplementary law. The second, a strategic approach, raise questions about the trajectory of the politics for the sector in search for the constitutional guarantee of financing. It also tries to understand how a well succeed movement find so many troubles to implement a constitutional conquest. We also enquire the support that the Brazilian society, represented by its elected governments, gives to the SUS. The meeting point of all these questions is the beginning of the rising of points for the short time regulation and building elements for the Sistema agenda. We do not intend to do an exhaustive analysis of the present subject, in spite of this, we are simply giving a list of questions to implement the debate.

\section{Key-words}

Monetary support, public politics for health, management.

\section{INTRODUÇÃO}

A trajetória bem-sucedida percorrida pelo Sistema Único de Saúde - SUS, desde a Constituinte de 86 , revela como segmentos da sociedade brasileira se 
mostraram capazes de mobilizar e articular forças políticas, de diferentes matizes ideológico-partidários, suficientes para gravar no texto constitucional os princípios da reforma sanitária e, depois, transformá-los em um dos raros casos de uma política pública que manteve o mesmo norte a despeito das sucessivas alterações de governo nos niveis municipal, estadual e federal. Se por um lado, é possivel registrar o êxito na definição e implementação do arcabouço institucional do SUS, por outro, o mesmo não se pode afirmar sobre um modelo de financiamento capaz de assegurar recursos necessários à sua manutenção.

Periodicamente o país se defronta com a precariedade do financiamento da política de saúde. De forma crônica, a situação tem se manifestado sob diferentes nuances: os conflitos entre cidades pólos e as satélites sobre fluxo assistencial e o correspondente aporte financeiro, a crise financeira do segmento hospitalar, a discussão em torno dos valores de remuneração dos serviços prestados ao SUS, as comparações internacionais entre os níveis de dispêndio do setor público para com a saúde, e a própria incapacidade do Sistema em atender, de forma integral, a demanda crescente por serviços de saúde pela população.

O atual debate acerca do financiamento da política pública de saúde encontra na implementação e regulamentação da Emenda Constitucional n. 29, de 2000 , seu principal mote. Trata-se de questão estratégica cujo desfecho provocará desdobramentos decisivos para a construção do Sistema Único de Saúde.

Propõe-se a abordagem dessa discussão em dois níveis: $O$ primeiro, de enfoque tático-conjuntural, situa-se em torno da Emenda propriamente dita e de sua regulamentação. As questões concentram-se na natureza do avanço conquistado com a sua promulgação e os riscos de retrocesso na elaboração da lei complementar. É possível entendê-la como uma medida que, ao mesmo tempo, proporciona previsibilidade de recursos, mas também define limites à política. O segundo, de caráter estratégico, problematiza a própria trajetória perseguida pela política setorial em busca da garantia constitucional do financiamento. Procura-se entender como um movimento tão bem sucedido enfrenta dificuldades na operacionalização de uma conquista constitucional. Indagase a sustentação que a sociedade brasileira, mediante seus governos eleitos, fornece ao Sistema Único de Saúde. Do encontro dessas vertentes, depreende-se contribuições para o enfrentamento da questão da regulamentação no curto prazo e enseja elementos para a agenda de construção do Sistema. Não se empreende uma análise exaustiva das questões apresentadas mas apenas um inventário de questões a título de contribuição ao debate.

\section{A EMENDA CONSTITUCIONAL N. 29 - AVANÇOS E LIMITES AO FINANCIAMENTO DA SAÚDE}

A Emenda Constitucional n. 29 tem suas origens na crise do financiamento da Saúde ocorrida no início dos anos 90 . Já no texto constitucional de 
1988 há previsão de destinação de parte do Orçamento da Seguridade Social ao financiamento da Saúde. O art. 55 dos Atos das Disposições Constitucionais Transitórias - ADCT, define esse percentual mínimo em 30\% até a elaboração da Lei de Diretrizes Orçamentárias. A combinação de alterações institucionais e a ampliação do déficit na Previdência Social ensejaram o não-cumprimento dessa previsão privando a Saúde dos recursos necessários ao seu custeio. Desenvolveu-se então, estratégia para assegurar um aporte financeiro mais previsível e em montante adequado, que redundou em propostas legislativas de criação de tributos especializados para o setor e de alteração do texto constitucional.

O texto aprovado pelo Congresso Nacional reflete um delicado equilíbrio obtido a partir da construção de um arco de alianças que abrangeu parlamentares de diferentes partidos, representantes de interesses profissional-corporativos, representantes do complexo produtivo da saúde, militantes da reforma sanitária, o executivo federal por meio do Ministério da Saúde - com resistências da área econômica, e hesitação dos executivos estaduais. Da construção do texto possível, emergiram conquistas que alteram o patamar em que ocorre o debate sobre o financiamento da política pública de saúde.

O compartilhamento genérico da obrigação pela provisão dos serviços públicos de saúde presente na Carta de 1988 é traduzido em co-responsabilidade financeira mínima, definida pela capacidade fiscal de Estados e municípios e pela evolução nominal da riqueza nacional, no caso da União. Não se discute mais o desempenho e destinação de fonte ou orçamento específico, mas sim o montante destinado ao setor de acordo com as possibilidades fiscais locais e regionais e a ação distributiva da União a partir da indexação, ainda que transitoriamente, do gasto federal ao nível da atividade econômica do país.

A garantia de patamares mínimos de recursos ao setor inscreve simultaneamente na agenda política a noção de limite e a busca pela aplicação ótima dos mesmos. A estrutura lógica do incentivo subtendida na regra é contundente: qualquer alocação adicional de recursos, além do mínimo previsto, depende da demonstração do uso adequado e da necessidade comprovada de expansão de serviços.

A possibilidade de revisão periódica dos montantes mínimos de aplicação reforça este argumento, pois impõe ao SUS um processo de contínua avaliação para a definição do nível de investimentos. Esse ciclo de avaliação permite correções acerca do montante global e da contribuição de cada esfera de governo, minimizando eventuais distorções e propiciando ajustes entre a capacidade de financiamento e a expansão dos serviços. Chamar a sociedade, a cada cinco anos, para definir o nível mínimo de recursos públicos destinados ao setor, também implica no questionamento sempre presente acerca do desempenho e da legitimidade da política de saúde. 
Cabe ao setor organizar o melhor serviço público de saúde possível com os recursos constitucionalmente disponíveis, considerando os princípios de eqüidade, universalidade e integralidade. Assim, como direito social cuja realização é progressiva, constitui dever do Estado instituir agenda de construção do sistema definindo etapas e horizonte temporal para os avanços da política pública.

A interpretação extremada dos princípios constitucionais de que o direito à saúde corresponde ao "tudo a todos, aqui e agora", sem regulação técnica, desprezando consensos terapêuticos, ou uma agenda de prioridades que assegure o interesse público, inviabiliza, ou no mínimo posterga indefinidamente, a construção de um Sistema Único de Saúde que de fato assegure o direito à saúde para todos. Trata-se de um conflito alocativo entre ações de saúde de caráter coletivo e de caráter individual, com conseqüências imediatas sobre a capacidade de oferta de serviços pelo poder público. $\mathrm{O}$ argumento é singelo: dado um montante financeiro finito, toda decisão que oriente a aplicação de recursos para ações em desacordo com o interesse público ocorre com prejuízo de muitos. Face ao desatino da focalização e de decisões desorganizadoras impõe-se a explicitação e institucionalização da agenda nacional, eventualmente positivada a partir de instrumento legislativo, que detalhe as diretrizes e princípios para a materialização e garantia do acesso progressivo aos serviços de saúde.

$\mathrm{Na}$ perspectiva da definição das prioridades na alocação dos recursos, registre-se ainda a introdução no texto constitucional das diretrizes da eqüidade no financiamento com objetivo de redução das disparidades regionais e a garantia transitória de financiamento para a atenção básica. Essas diretrizes agregam-se às outras já gravadas na Constituição: a organização regionalizada e hierarquizada dos equipamentos de saúde, a descentralização e a direção única em cada nível de governo, a preferência pelas ações preventivas e a participação da sociedade civil.

\section{A Regulamentação}

A Lei Complementar prevista pela Emenda deverá disciplinar a abrangência da expressão "ações e serviços públicos de saúde", a definição do montante a ser aplicado pelas três esferas de governo para o próximo período de cinco anos, estabelecendo o dispositivo a ser aplicado pela União e os percentuais de Estados e municípios, a natureza das eventuais sanções e medidas reparadoras aplicáveis em caso de descumprimento por algum ente, e os instrumentos para o acompanhamento e fiscalização pelas instâncias de controle social.

A ausência da regulamentação tem ensejado o debate acerca do cumprimento ou não do mandamento constitucional pelos entes federados e a 
eficácia da regulamentação existente, definida pelas instâncias de regulamentação do sistema. Contudo, considerando a auto-aplicabilidade e o teor das disposições do texto constitucional, da legislação ordinária vigente, em especial as Leis Federais ns. 8.080, de 19 de setembro de 1990, e 8.142, de 28 de dezembro de 1990, e o desenvolvimento institucional do Sistema Único de Saúde, constata-se a existência de acúmulo suficiente para balizar o processo de elaboração legislativo e o prosseguimento da implementação da emenda nesse interregno.

Dentre as matérias que a lei complementar deverá disciplinar, ressaltam-se duas questões em que a sociedade brasileira terá de assumir opções estratégicas. A primeira diz respeito a intersetorialidade da política pública de saúde. A definição da extensão dos gastos públicos que podem ser considerados como legítimas "ações e serviços públicos de saúde" posiciona a política pública diante de um dilema. Primeiro faz-se necessário o descarte de iniciativas das áreas econômicas que consideram como ação de saúde pública o pagamento de benefícios previdenciários, serviços públicos financiados por contraprestação pecuniária pelo usuário, serviços ofertados a "clientela fechada" e não à população em geral. Depois, identificar as áreas limítrofes onde pode haver interesse de ação intersetorial orientada pelas prioridades da saúde pública. Neste caso, abre-se a possibilidade de trazê-las para o âmbito institucional do SUS, submetendo-as à gestão compartilhada e pactuada e ao controle social. Dilema entre um conceito restritivo que maximize recursos para ações tradicionais e outro que amplie a desejável ação intersetorial.

A segunda é a definição da natureza da vinculação dos recursos federais. A vinculação transitória à evolução nominal do Produto Interno Bruto assegura a manutenção do valor real destinado pela União à saúde, uma vez que incorpora a inflação, assim como permite que o incremento real da riqueza do país seja compartilhado com o sistema. Trata-se de uma clara estratégia distributiva, balizada por indicador de cálculo conhecido e independente. Alternativas exploradas no passado, associadas à instituição de fonte especializada, vinculação de percentual do orçamento ou da receita não asseguram a mesma estabilidade ao longo do tempo e independência em relação à administração fazendária. Desde a década de 90 , a trajetória da receita corrente da União vem sendo marcada pela ampliação real da carga tributária em relação ao PIB e a concentração dos recursos no nível federal mediante a criação de tributos não compartilháveis com os demais entes. As crescentes pressões de Estados e municípios para compartilhamento da receita tributária e a demanda social por uma agenda de expansão econômica são sintomas de que, tanto a concentração da carga tributária na União quanto sua participação relativa no PIB, encontram-se próximos de seus extremos. Diante deste cenário, não parece razoável apostar no desempenho da carga tributária para os próximos anos, semelhante ao da década passada. 
A evolução do debate a respeito da regulamentação e implementação da Emenda $n$. 29, tem revelado a necessidade de realizar ganhos qualitativos na estratégia de acompanhamento e controle. Não só por exigir ação integrada das instâncias de controle social, tribunais de contas, conselhos de saúde e Ministério Público, mas, e principalmente, pela necessidade de disseminação dos princípios e normalização do SUS junto a estes parceiros estratégicos. Os desafios para implantação dos fundos de saúde, a demonstração dos gastos, a discussão do conceito e abrangência da ação da política pública de saúde têm promovido também um maior e necessário espraiamento do conhecimento do SUS para as áreas de planejamento e finanças do setor público e, é possível afirmar, para dentro do próprio setor da saúde.

\section{DESAFIOS À EXPANSÃO DO GASTO PÚBLICO COM SAÚDE}

A expansão do gasto público com a saúde enfrenta o quadro geral de crise fiscal a que está submetido o estado brasileiro. $O$ constrangimento fiscal da peça orçamentária é caracterizado pela perspectiva das dificuldades de aumento de arrecadação, dada a elevada carga tributária concentrada na União e pelas múltiplas demandas a que está submetido. Demandas por ampliação dos serviços públicos dada a elevada dívida social e pelo pagamento dos encargos decorrentes da elevada dívida financeira pública.

No campo político-partidário-ideológico, à direita ou à esquerda, não faltam defensores de posições contrárias às estratégias que promovam a vinculação de recursos a qualquer área das políticas públicas. São apresentados diversos argumentos dentre os quais a frágil capacidade fiscal do setor público, a eventual perda de eficiência setorial pela existência de recursos garantidos, ou ainda, quanto menor a rigidez orçamentária, maior o grau de liberdade para que governos democraticamente eleitos possam direcionar os recursos públicos ao atendimento das prioridades. Ora, como as prioridades se configuram conjunturalmente ao longo do tempo, a ampla liberdade orçamentária criaria condições para a alocação dos recursos públicos de acordo com as demandas sociais traduzidas pelos programas de governo legitimamente eleitos.

Entretanto, a peça orçamentária deve ser compreendida como resultado histórico do conflito distributivo que se estabelece entre os atores sociais pela alocação de recursos nas diferentes políticas públicas. Apresenta algum grau de inércia em função da cristalização de interesses de atores sociais beneficiados ou envolvidos na sua execução, da legitimidade social da política pública, ou ainda da capacidade dos atores de mobilizar recursos de poder que influenciem o processo decisório governamental, envolvendo executivo e legislativo. Dessa forma, a alocação alternativa de recursos ou seu redirecionamento envolvem complexas ações políticas e operacio- 
nais no desenho das políticas públicas. Agenda de prioridades legitimamente construídas eleitoralmente por partidos políticos e pela sociedade constituem oportunidades ímpares para a construção dessas alternativas. Por outro lado, a estruturação do Sistema Único de Saúde como política de saúde universalista, assegurando a integralidade a todos os cidadãos brasileiros, não decorre de uma pauta conjuntural, mas de projeto de natureza estrutural para o estado brasileiro, tarefa que transcende a obra política de uma geração.

As decisões nos últimos anos sobre o orçamento foram tomadas em um contexto marcado pela restrição fiscal, vulnerabilidade externa da economia, perda de graus de liberdade na gestão fiscal face às expectativas da comunidade financeira internacional, levando a um "enrijecimento" do gasto público pela necessidade de saldar o serviço da dívida.

Considerando esse contexto e o quadro geral de recursos destinados às políticas públicas no Brasil, é preciso reconhecer que o cenário do financiamento da saúde é de escassez relativa. Há necessidade de ampliar os recursos ao setor para assegurar a estabilidade operacional, num quadro de sub-financiamento, e para prosseguir na construção do projeto inscrito na Constituição. A persistência de um quadro de subfinanciamento e paralisação na evolução do acesso ao direito à saúde representa um grave risco, uma vez que pode fragilizar a opção estratégica da sociedade por uma política que se propõe universal e integral. Contudo, em termos comparativos com as demais políticas públicas implementadas no país, não há como negar o expressivo montante destinado pelas três esferas de governo à saúde ${ }^{(1)}$.

O alcance desse patamar de gastos, associado à própria aprovação da emenda, revela êxito e capacidade de mobilização política dos atores envolvidos. Entretanto, as dificuldades enfrentadas na implementação revelam que se há forte sensibilidade da opinião pública para a questão da saúde, não há a mesma percepção ou unanimidade acerca da alocação de recursos adicionais. A alteração desse limite exige uma opção política da sociedade brasileira que extrapola as forças mobilizadas para a aprovação do texto constitucional em 88, e da emenda em 2000.

A compreensão desse estado de coisas envolve a análise de diferentes modelos explicativos e o exame de diversas variáveis num esforço de complexidade considerável. Restringimo-nos, entretanto, às conseqüências sobre o financiamento. Quaisquer que sejam as razões, importa a conseqüência, o fato de que a política pública por si só, pelo seu mérito, pelos seus efeitos, benefícios e relevância, envolvendo os diversos atores sociais

(1) Segundo estimativa realizada a partir de dados informados ao Sistema de Informações de Orçamentos Públicos em Saúde - SIOPS, o gasto das três esferas com saúde situa-se em torno de $\mathrm{R} \$ 60$ bilhões. 
- gestores, usuários, trabalhadores, prestadores de serviço e empresas do complexo produtivo - não conseguiu mobilizar e exercer pressão suficiente para, até o momento, construir solução estável para seu financiamento.

Considerando que a opinião pública é inclemente quando seus interesses diretos são negligenciados, tem-se que a superação dessa etapa só se dará com a mobilização de ampla frente política, de formadores de opinião, da sociedade civil organizada, tendo por substrato um "pacto pela saúde" firmado com os diferentes segmentos, capaz de proporcionar legitimidade e êxito à iniciativa. A construção dessa mobilização passa pela superação de desafios internos ao SUS associados a incrementos no acesso do cidadão aos serviços e à capacidade de organização e gestão da política de saúde.

\section{ORGANIZAÇÃO, GESTÃO E FINANCIAMENTO}

Os princípios para organização da política de saúde são conhecidos e derivam das premissas estabelecidas na constituição: a necessidade de inversão do modelo com a ênfase na atenção básica e a organização dos aparelhos de saúde em uma rede regionalizada e hierarquizada conforme 0 grau de complexidade. As ações e o desenho da rede de serviços devem ser capazes de, do ponto de vista da atenção à saúde, promover o acesso e a qualidade na prestação dos cuidados ao cidadão, mas, também, estarem organizados de acordo com premissas de eficiência econômica que propiciem ganhos de escala e escopo ao processo produtivo dos serviços de saúde.

A existência de uma rede geograficamente organizada em regiões assistenciais, conforme o nível de complexidade, deve espelhar a busca pelo equilíbrio entre a garantia do acesso e a maximização da eficiência econômica. Trata-se de premissa essencial a partir da qual estrutura-se a ação do gestor público na construção da política pública. Daí derivam as bases para os esforços de racionalização e regulação do sistema, as diretrizes para incorporação tecnológica, as diretrizes para os investimentos diretos do poder público ou não, dentre inúmeras outras ações. Registre-se, neste sentido, a publicação da Norma Operacional de Assistência à Saúde - NOAS, n. 01, de 2002, que prevê a elaboração do Plano Diretor de Regionalização e do Plano Diretor de Investimentos incorporando. Os princípios e diretrizes são conhecidos, a sua incorporação enquanto prática política-administrativa ainda é recente e desigual.

A organização do espaço assistencial em uma rede descentralizada, regionalizada e hierarquizada tem implicações no papel e na complementaridade dos esforços entre os municípios e o Estado. Se ao município cabe assegurar a atenção básica resolutiva, à microrregião a média complexida- 
de e à macrorregião a alta complexidade, necessariamente, o funcionamento do sistema requer uma forte ação cooperativa entre os municípios e entre estes e o nível estadual. A existência de auto-suficiência no território municipal constitui exceção dentre o conjunto de municípios brasileiros. Assim, avanços sistêmicos e sustentáveis do acesso e da qualidade da atenção serão frutos de ação conjunta dos entes federados num dado espaço assistencial.

Faz-se necessária a explicitação de um pacto em torno da definição e responsabilidades de cada esfera de governo: um "contrato" que potencialize a ação cooperativa e solidária, mas também permita avaliação e sanções, uma estrutura de incentivos que fortaleça a coesão sistêmica e os ganhos na provisão dos serviços. Se a responsabilidade pela provisão da atenção básica é do município cabe ao nível estadual a função de avaliação "externa" e apoio para os esforços de qualificação.

A tensão distributiva que ocorre entre municípios "pólo" e "satélite" em torno dos fluxos assistenciais e seu correspondente aporte financeiro, revela como a garantia do acesso ao cidadão é frágil atualmente. A análise dessa situação tem, via de regra, limitado-se a questões como a insuficiência dos valores de remuneração para a provisão dos serviços, a ausência de controle e avaliação dos fluxos de referência e contra-referência, a ausência de atenção básica de qualidade no município satélite. A despeito dessas razões, o ponto central tem sido relegado, qual seja a desvinculação entre a responsabilidade pela estado de saúde do cidadão e a gestão dos recursos para financiar a assistência.

A responsabilidade pelo estado de saúde de uma dada população tem como referência o espaço político-administrativo em que se localiza, uma vez que o mandato popular se dá no âmbito desse perímetro. Assim, secretário municipal de saúde de uma cidade, ainda que habilitada na modalidade em gestão plena do sistema, não deveria ter poderes para decidir sobre a aplicação dos recursos de uma outra cidade. $O$ atual formato desobriga o real responsável pela saúde do indivíduo que é o seu município de origem, e onera o município que o recebe que, com freqüência, tem parte de seu orçamento comprometido com os cuidados de população não residente. Dessa situação surgem conflitos e periodicamente as referências não são confirmadas e as "portas são fechadas" aos cidadãos não residentes. O secretário do município de origem afirma que os recursos financeiros correspondentes aos serviços foram alocados ao município de referência, por meio da Programação Pactuada Integrada; o secretário de saúde do município de referência afirma que os recursos são insuficientes para arcar com os custos de provisão dos serviços, ambos tem razão e são "desonerados" do problema. O cidadão fica sem os serviços e a quem recorrer. $O$ contrato é frágil e na perspectiva do cidadão esta é uma situação inaceitável.

Como a organização do espaço assistencial extrapola as fronteiras municipais, faz-se necessário o aprimoramento da instância e da natureza 
da pactuação dos fluxos no âmbito das regiões assistenciais. A organização de Comissões Intergestoras Bipartites macro e microrregionais é um passo nesse sentido. Se há necessidade de se realizar ajustes locais entre os recursos disponíveis e a provisão dos serviços, deve-se explicitar a questão e não escamoteá-la. A sociedade uma vez chamada ao debate poderá analisar e posicionar-se sobre a questão. A discussão sobre a responsabilização da gestão local e a definição de regra clara para financiamento da assistência com alocação tripartite dos recursos, onde Estados e União exerçam papel distributivo, constituem pontos imprescindíveis neste debate.

O modelo de distribuição de recursos reflete a construção histórica de uma alocação com base na capacidade instalada e na produção de serviços. Constitui atualmente uma estrutura de incentivos fragmentada e contraditória que produz iniqüidade entre as diversas regiões. Trata-se de questões que remetem ao art. $n$. 35 da Lei n. 8.080/90, mas que ainda não se transformaram em ação concreta incorporada à política de saúde. Faz-se necessária a construção de sistemática que permita alocação progressiva de acordo com as necessidades da população, organizadas pelo espaço assistencial e não de acordo com a capacidade de oferta. Ao se contemplar progressivamente critérios que promovam a eqüidade, reduzindo as desigualdades pela alocação de recursos de acordo com a necessidade da população por serviços de saúde, não se pode negligenciar o necessário redimensionamento e regionalização da rede de serviços, assim como a avaliação de eficiência e eficácia, permitindo um caminho de mão dupla para os casos de realocação decorrentes de desempenho insuficiente.

A participação social por meio dos conselhos de saúde deve ser continuamente revigorada. Faz-se necessário assegurar informações e meios para o exercício das prerrogativas do controle social. As regras de composição e representação nos conselhos devem mobilizar e continuamente ampliar a participação da sociedade civil estimulando a renovação.

Talvez em função do viés histórico anterior a 88 , talvez pela complexidade operacional, ou traços de disfuncionalidade burocrática, é possível observar excessos na construção normativa do sistema com ênfase no gerenciamento e financiamento de facetas da oferta dos serviços de saúde, perdendo-se o foco do cidadão.

\section{COMENTÁRIOS FINAIS}

O Sistema Único de Saúde construiu a partir dos anos 80 uma posição hegemônica do ponto de vista do arcabouço institucional e do formato da política pública no setor saúde. Não há política setorial concorrente, o 
único esboço de experiência alternativa ao SUS se restringiu a um pequeno espaço de tempo na cidade de São Paulo. Não há grupamento partidário que tenha em seu conteúdo programático a substituição do modelo. Contudo, também não há definição inequívoca da sociedade acerca da alocação de recursos suficiente à manutenção e subseqüente expansão do modelo. Configura-se uma certa contradição ou hesitação que, se mantida ao longo do tempo, pode implicar no questionamento do modelo e em sua inviabilidade.

Observados os princípios constitucionais de universalidade, integralidade e eqüidade, cabe ao Estado a definição de agenda para a implementação de políticas públicas que progressivamente propiciem a plena realização do direito do cidadão ao acesso aos serviços de saúde. Contudo, dado o contexto nacional marcado, por um lado, pela existência de múltiplas e urgentes demandas sociais e, por outro, por um quadro de escassez relativa com restrições à capacidade fiscal para alocação de recursos adicionais, impõe-se ao Sistema Único de Saúde o enfrentamento de questões indissociáveis à necessidade de implementar ganhos na capacidade de gestão da política setorial.

A discussão do financiamento impõe duplo desafio: assegurar regulamentação e implementação da EC n. 29/2000, que não impliquem em retrocesso no montante de recursos nem nos princípios que orientam a construção da política, e empreender construção política junto à sociedade que permita ampliar o atual patamar de financiamento. A inter-relação entre as duas abordagens demonstra, a necessidade de definição de uma agenda clara que amplie a base de sustentação social.

As dificuldades para se conquistar patamar de financiamento adequado, guardam relação direta com incertezas acerca da capacidade do sistema em cumprir adequadamente sua missão. É preciso transbordar o êxito autocentrado conquistado pelo sistema na trajetória percorrida desde a sua criação, para a opinião pública em geral.

Não decorre dessa assertiva uma inversão de pautas ou estratégia para a construção do sistema, mas o reconhecimento de pautas simultâneas onde avanços em um campo reforçem a tese e permitem avanços noutro. 